\title{
The differences of movement between children at risk of developmental coordination disorder and those not at risk
}

\author{
Adrián Agricola*, Rudolf Psotta, Reza Abdollahipour, and Miriam Palomo Nieto \\ Faculty of Physical Culture, Palacký University Olomouc, Olomouc, Czech Republic
}

Copyright: (c) 2015 A. Agricola et al. This is an open access article licensed under the Creative Commons Attribution License (http://creativecommons.org/licenses/by/4.0/).

\begin{abstract}
Background: Developmental coordination disorder (DCD) is a syndrome unexplained by medical condition, which is marked by defects in the development of motor coordination. Children with this impairment are more dependent on visual information to perform movements than their typically developing (TD) peers. Objective: The main aim of the research was to create a checklist for the evaluation of the head and limb movement while walking. After that, based on this tool, to find differences in the movement of various body segments in children at risk of DCD (DCD $)$ compared to typically developing children under different visual conditions. Methods: A total of 32 children aged $8.7 \pm 1.1$ years participated in this study. The Movement Assessment Battery for Children $-2^{\text {nd }}$ edition (MABC-2) was used to make a classification of motor competence level of the participants. PLATO goggles were used to make four different visual conditions. All trials were recorded. Based on the video analysis we completed a qualitative checklist. Results: The analysis between the children from the $\mathrm{DCD}_{\mathrm{r}}$ group and TD children showed significant differences in the head $(p=.023)$ and the arm $(p=.005)$ movements, in body position $(p=.002)$ and total summary score $(p=.001)$. The main effects of visual conditions showed significant differences in all cases; in the head $(p=.015)$, with the arm $(p=.006)$, trunk $(p=.009)$, leg $(p=.001)$ movements, in body position $(\mathrm{p}=.001)$ and also in the total summary score $(p=.001)$. The interaction between groups and visual conditions was significant in leg movements $(p=.007)$ and body position $(p=.002)$. Conclusions: This study has shown which movements of body segments are most affected by different visual conditions and how children at risk of DCD are dependent on visual perception.
\end{abstract}

Keywords: motor impairment, motion, vision, videoanalysis, checklist

\section{Introduction}

The American Psychiatric Association (APA) agreed to use the term developmental coordination disorder (DCD) for children with specific developmental disorder of motor functions, which do not stem from a medical condition. These children do not have any intellectual problems or delays, which should increase their motor coordination difficulties (American Psychiatric Association, 2013). Children with motor impairments, also called motor skills disorder, coordination disorder, lack of coordination or clumsy children, show motor difficulties and learning impairment which interfere with their daily living activities (Bo \& Lee, 2013; Cermak, Gubbay, \& Larkin, 2002; Polatajko, 1999).

\footnotetext{
* Address for correspondence: Adrián Agricola, Department of Natural Sciences in Kinanthropology, Faculty of Physical Culture, Palacký University Olomouc, třída Míru 117, 77111 Olomouc, Czech Republic. E-mail: adrian.agricola@gmail.com
}

Some studies related to movement describe the importance of vision for proper motor coordination (Deconinck et al., 2006a; Missiuna, Rivard, \& Bartlett, 2003). Vision is the primary source, which brain uses for receiving information from the environment (Cheatum \& Hammond, 2000; Coetzee \& Pienaar, 2010). The motor skills are negatively affected if this sensory input system works ineffectively. Some studies have also shown that DCD are more dependent on visual information to perform basic movements such as walking, running or throwing than their typically developing (TD) peers (Deconinck et al., 2006a; Missiuna et al., 2003; Smyth, Anderson, \& Churchill, 2001). Since the visual information in motor control is crucial in the majority of human movement, it could be assumed, that movements are impaired in this group of children (Schoemaker, van der Wees, Flapper, Verheij-Jansen, Scholten-Jaegers, \& Geuze, 2001), because it was shown, that the greatest deficiency in these patients is in visual spatial processing (Wilson \& MacKenzie, 
1998). Wann, Mon-Williams, and Carson (1998) have shown a bigger dependence of children with DCD from visual information even in static positions. For example, children were standing on one place and their postural sway (anteroposterior and lateral movements of the body) was more affected by the removal of vision.

Larkin and Hoare (1991) noted, that abnormal head positions, poor posture, bent arms in the guard position, jerky limb to limb transitions, excessive hip flexion, pronounced asymmetry, and a wide base of support are typical symptoms for children with DCD while walking. Children with DCD have a tendency to look downward and their head is not in an upright position. Arm movements are not swinging in the sagittal plane in opposition to the legs, and children with DCD often do not use the arms while walking (Henderson, Sugden, \& Barnett, 2007). There were observed large deviations in some cases in the arms positions and movements and elbow positions from a normal range between DCD children and TD children (Larkin \& Hoare, 1991). The trunk of DCD children is often in a forward or backward position, accompanied by stronger lateral or anteroposterior movements (Deconinck et al., 2006a). In the movements of the legs were observed problems with insufficient knee flexion and extension, irregular transition from limb to limb, wide base of support and walking on the toes rather than heel - toe. In general, the whole movement of children with DCD does not seem safe. Children with DCD have problems with balance while walking and changing directions is a difficult challenge for them (Deconinck et al., 2006a).

Walking of children with DCD is often described as wooden, stiff or awkward (Deconinck et al., 2006a; Parker \& Larkin, 2003). Rosengren et al. (2009) has shown that children with DCD have more difficulty controlling their lower limbs than TD children. He also reported greater variability in the movement of the legs in children with DCD. A different symmetry in movements between the right leg and the left leg was not found. However, follow-up analyses exploring the differences between legs, found significantly greater differences in the variability across the two limbs for children with DCD. Raynor (2001) has shown that children with DCD have neuromuscular problems including lower levels of muscle strength and power and increased levels of coactivation of muscle groups during a knee flexion task. Lundy-Ekman, Ivry, Keele, and Woollacott (1991) found similar neuromuscular problems, indicating difficulties with the selective muscle control necessary for rhythmic coordination. Deconinck et al. (2006b) reported that walking of DCD children is characterized by shorter steps, greater trunk inclination, decreased ankle flexion and more variable thigh and shank movement than TD children. He also adds that these behavioural adaptations while walking in children with DCD indicates a greater reliance on visual information.

Macnab, Miller, and Polatajko (2001) reported, that walking problems are closely connected with proprioceptive deficits and balance dysfunction, which are also typical for motor dyspraxia. These are one of the most common sensorimotor impairments observed among children with DCD. Indeed, it was reported, that $73-87 \%$ of children with DCD have balance problems (Macnab et al., 2001). A correct postural balance requires an active sensorimotor control system, based on the afferent system, which supports a balance of the proprioceptive, vestibular and visual system (Steindl, Kunz, Schrott-Foscher, \& Scholz, 2006). Balance problems might not be surprising, because visual spatial processing, kinesthetic integration and kinesthetic perception have an important role for successful maintenance of stability, but they are all often reported with children with DCD (Wilson \& MacKenzie, 1998).

There is often a view that these children do not need special attention because they will overcome these difficulties with time. However, some longitudinal studies (Cousins \& Smyth, 2003; Gillberg, Gillberg, \& Groth, 1989; Hellgren, Gillberg, Gillberg, \& Enerskog, 1993) rejected this supposition and pointed out, that these problems have persisted into adulthood and have been associated with DCD. Therefore it is important to work with these children from an early age. However, the motor-level identification of children may be a problem for schools or after-school clubs. Therefore the aim of this study was to develop a qualitative checklist to rapidly identify movement problems in children while walking. The second aim was to use this checklist in clinical practice and describe the differences in the movement of the head and limbs among children at risk of DCD and TD children under different visual conditions.

\section{Methods}

\section{Participants}

The ethical approval to conduct this research was obtained from the Ethics Committee of the Faculty of Physical Culture, Palacký University Olomouc. A written consent was obtained from parents of the participants and from school principals. The children were informed about the experiment at their schools by theirclass teachers and/or school psychologists.

Participants were selected from 397 children who were attending five typical elementary schools. All of these children were screened by the school psychologist 
in cooperation with the teachers of physical education. The aim was to find children with postural deficits and motor difficulties. Based on their recommendations a motor competence of selected participants was assessed by using the Motor Assessment Testing Battery $-2^{\text {nd }}$ version (see below). The results showed that 16 participants have motor difficulties which can be connected with DCD. However, these results cannot be the evidence of the presence of DCD without additional clinical examination. Also some individuals reached a score which indicates the deterioration of motor function thus not directly an acute threat of DCD. Yet, they are "at risk" according to Henderson, Barnett, and Henderson (1994) because of that the term "risk of DCD" $\left(\mathrm{DCD}_{\mathrm{r}}\right)$ was chosen for this group.

Later, due to this research, we created a group with TD. There were children $(n=16)$ who had no motor difficulties based on the result of MABC-2.

\section{Qualitative checklist}

The qualitative checklist (Figure 1) was created specifically for this research. This checklist employed motor observation to describe and analyze the quality of movements while a participant walks. All items of the checklist were chosen based on reports from scientific studies (Deconinck et al., 2006a, 2006b; Henderson et al., 1994; Larkin \& Hoare, 1991), which have focused on an incorrect positions or movements of the body segments (head, arm, trunk, leg movements and whole body position) in children with DCD or at risk of this impairment.

The qualitative checklist contained 21 items (which focused on a technique and quality of motion) which were divided into 5 groups (head movements, arm movements, trunk movements, leg movements and body position). If a motion was made correctly, a positive point was added to the item. If the movement was made incorrectly (incorrect movement was executed more than two times in one trial) a negative point was added to the item (Henderson \& Sugden, 1992). Finally, all the negative points were counted for each visual condition separately and also together.

The validity of the checklist was approved based on consistent results with the MABC-2 results. It means, that the children who were classified into the $\mathrm{DCD}_{\mathrm{r}}$ group based on the total test score (TTS) from the MABC-2 also achieved a significantly lower score $(p=.017)$ in this qualitative checklist than their typically developing peers. Interrater reliability between two independent researchers (observers) showed a high correlation $(r=.91)$.

\section{Instruments}

Anthropometric assessment

Before the experiment, the body height and body weight of all participants were measured. The body height was measured by Leicester Height Measure Mk II (Invicta Plastic Limited, Leicester, UK) with an accuracy of $0.1 \mathrm{~cm}$. For measuring the body weight we used the digital scale Tanita BF-350 (Tanita, Tokyo, Japan) with an accuracy of $0.1 \mathrm{~kg}$.

\section{Motor assessment}

To assess motor coordination the MABC-2 test, age version AB2 (Henderson et al., 1994) was used. The test involves the following eight tasks - placing pegs, threading lace, and drawing a trail for the assessment of manual dexterity; catching and throwing bean-bags onto a mat tests for gross motor coordination, and one board balance, heel-to-toe walking, and hopping on mats for the balance component.

Raw scores achieved by each child in the particular items were transferred into age-normalized item standard scores according to the age norms established for the population of the Czech children (Psotta, Hendl, Frömel, \& Lehnert, 2012). The TTS, calculated as the sum of item test scores, was also transferred on the agenormalized component standard score and percentile equivalent. According to the diagnostic rules stated in the Manual of the MABC-2 (Henderson et al., 1994) a child whose TTS falls below the $15^{\text {th }}$ percentile and higher than $5^{\text {th }}$ percentile is identified as a subject being at risk of having DCD and those with TTS $\leq 5^{\text {th }}$ percentile as children with the significant motor difficulties which almost certainly corresponds to DCD. All children falling into these two groups were involved in this experiment in the $\mathrm{DCD}_{\mathrm{r}}$ group. The child, who has achieved TTS $>15^{\text {th }}$ was considered as a participant without motor difficulties and included into the TD group.

\section{High definition (HD) cameras}

Two HD Panasonic TM900 camcorders (Panasonic, Osaka, Japan), one at the beginning of the walkway and the other in the end, were used to record the participants while walking. All trials were recorded and later, based on the video analysis, were checked with the qualitative checklist.

\section{Portable laboratory}

The portable laboratory ( $15 \mathrm{~m}$ length and $4 \mathrm{~m}$ width) was specifically designed for the experiment. It was an aluminium construction and the whole structure was covered by dark fabric. The children could not be disturbed by the environment under these conditions. 


\begin{tabular}{|c|c|c|c|}
\hline NAME: & DATE : & $\mathbf{Y}$ & $\mathbf{N}$ \\
\hline \multicolumn{4}{|l|}{ HEAD } \\
\hline \multicolumn{2}{|c|}{ 1. Does not hold the head in an upright position. Look downward, not forward. } & & \\
\hline \multicolumn{3}{|c|}{ The head is always in a downward position and the look is downward. } & \\
\hline \multicolumn{2}{|l|}{ 2. Extra movements (anteroposterior). } & & \\
\hline \multicolumn{3}{|l|}{ The head never is in an upright position, completely vertical. } & \\
\hline \multicolumn{2}{|l|}{ 3. Extra movements (lateral). } & & \\
\hline \multicolumn{3}{|l|}{ The head never is in an upright position, completely vertical. } & \\
\hline \multicolumn{2}{|l|}{ 4. Limited head movement. Head stiffness. } & & \\
\hline \multicolumn{3}{|l|}{ The head movement does not exist. The head is completely rigid. } & \\
\hline \multicolumn{3}{|l|}{ ARMS } & \\
\hline \multicolumn{2}{|c|}{ 5. Does not do arm swing in the sagittal plane in opposition to the legs. } & & \\
\hline \multicolumn{3}{|c|}{ More than two times arms don't go in opposition to the legs in the sagittal plane. } & \\
\hline \multicolumn{2}{|c|}{ 6. Arm movements are exaggerated. } & & \\
\hline \multicolumn{3}{|c|}{ The movement of the arms are not normal. There is a large deviation from the normal range. } & \\
\hline \multicolumn{2}{|l|}{ 7. Arm swing is rigid and moved from the shoulder. } & & \\
\hline \multicolumn{3}{|c|}{ The movement of the arms is completely rigid. No movement around the shoulder } & \\
\hline \multicolumn{2}{|l|}{ 8. Excessive elbow flexion, forearm in a high position. } & & \\
\hline \multicolumn{3}{|l|}{ Does an important elbow flexion. Hands up the level of the elbows } & \\
\hline \multicolumn{2}{|l|}{ 9. Does not use arms to assist the walking. } & & \\
\hline \multicolumn{3}{|l|}{ Arm movement disturbs the walking. } & \\
\hline \multicolumn{3}{|l|}{ TRUNK } & \\
\hline \multicolumn{2}{|c|}{ 10. Trunk inclination. The trunk appears remarkable forward or backward during the whole cycle } & & \\
\hline \multicolumn{3}{|c|}{ The trunk is in a forward or backward position-implies balance problems; high risk of falling. } & \\
\hline \multicolumn{2}{|c|}{ 11. Not erected trunk and strained. } & & \\
\hline The trunk is in an important backward, forward, or lateral positi & & & \\
\hline 12. Extra movements (anteroposterior). & & & \\
\hline Extra movement in the anteroposterior or lateral plane. The wal & s discontinuous. & & \\
\hline 13. Extra movements (lateral). & & & \\
\hline Extra movement in the anteroposterior or lateral plane. The wal & s discontinuous. & & \\
\hline LEGS & & & \\
\hline 15. Excessive knee flexion continuously. & & & \\
\hline The knee flexion is excessive and also continuously. & & & \\
\hline 16. Excessive knee extension continuously. & & & \\
\hline The knee extension is excessive and also continuously. & & & \\
\hline 17. Jerky or irregular transition from limb to limb. & & & \\
\hline The walking is completely irregular and always is required to be & & & \\
\hline 18. Wide base of support. & & & \\
\hline The wide base of support is highly smaller or bigger than the di & en the shoulders. & & \\
\hline 19. Walking on toes rather than heel - toe. & & & \\
\hline The change from the stance phase to the swing phase is done by & & & \\
\hline THE GENERAL DISPOSITION OF THE BODY & & & \\
\hline 20. The movement does not seem safe. & & & \\
\hline The walking is completely unsafe. The child has doubt about hi & to walk. & & \\
\hline 21. The child seems to lose his balance. & & & \\
\hline The child seems to be completely unbalanced. High risk to fall & & & \\
\hline
\end{tabular}

Figure 1. The qualitative checklist for evaluation of body segments movement 


\section{Shoes for participants}

All participants had the same type of canvas shoes (model Jarmilky; Toga, Hradište, Slovak Republic) in their required sizes.

\section{Procedure}

Before the experiment two researchers individually assessed the children on the MABC-2 test in a quiet room. Then anthropometric measurements of the selected children were measured. After these measurements, the children were randomly asked to walk at a comfortable speed along the 10 meter walkway inside a portable laboratory, which was located in a school gym. PLATO (Portable Liquid-Crystal Apparatus for Tachistoscopic Occlusion) (Translucent Technologies Inc., Toronto, Canada) system goggles were used to make different visual conditions, and they were shut and opened at different times. The control of the goggles was changed using a sender - receiver (Bluetooth) to allow for wireless control.

There were four visual conditions in this experiment: 1. Full vision (FV): the children walked without any special equipment; 2. Limited vision 100 (LV100): the children used the PLATO goggles, which were open 100 milliseconds and 2 seconds closed; 3. Limited vision 150 (LV150): the children used the PLATO goggles, which were open 150 milliseconds and 2 seconds closed; and, 4. Non vision (NV): the children's eyes were covered at all times by a headband.

Limited vision conditions LV100 and LV150 were selected on the basis of several studies, which reported $100 \mathrm{~ms}$ as a lowest value for visual processing (Paulignan, MacKenzie, Marteniuk, \& Jeannerod, 1991; Pélisson, Prablanc, Goodale, \& Jeannwerod, 1986). Some studies proved significant differences between the values of $100 \mathrm{~ms}$ and $150 \mathrm{~ms}$ (Carlton, 1981; Smith \& Bowen, 1980; Spijkers \& Lochner, 1994), which means that $150 \mathrm{~ms}$ was already sufficient time for visual processing. Therefore, these values were chosen to discover, whether differences will be significant in our groups, especially in the $\mathrm{DCD}_{\mathrm{r}}$ group.

\section{Data analysis}

The $t$-test was conducted to assess the age, the body weight and the body height of participants to ensure that the groups were not different in these particular variables at the beginning of test. Performance of participants emerged from the qualitative checklist and the sum of the scores of each observed body part was presented the dependent variable.

The Shapiro-Wilk test was used to assess normal distribution of data. Data were analyzed by 2 (groups: $\mathrm{DCD}_{\mathrm{r}}$ vs. TD) $\times 4$ (visual conditions: FV, LV150, LV100, NV) with repeated measures on last factor.
Mauchly's test was performed to evaluate the sphericity assumption. Greenhouse-Geisser epsilon values were used to adjust the degrees of freedom in the ANOVAs with repeated measures to compensate for deviations from the assumption of sphericity. The data analyses were performed using the SPSS statistical software (Version 21; IBM, Armonk, NY, USA).

\section{Results}

At the beginning of this study a checklist was verified in the pilot experiment - there were eight children, aged 7-10 (8.8 \pm 1.2 years). First, anthropometric measurements (body height and body weight) were taken. The MABC-2 was used for assessing the motor coordination level of participants. Based on the TTS three children $(9.0 \pm 0.9)$ were included in the $\mathrm{DCD}_{\mathrm{r}}$ group (TTS $\leq 15^{\text {th }}$ percentile) and five children $(8.7 \pm 1.3)$ in the TD group (TTS $>15^{\text {th }}$ percentile). Then, the portable laboratory with a special walkway was built in the school-gym. The children were asked to walk at their own speed under normal visual conditions. Later, in further trials, the PLATO goggles were used for changing the visual conditions. All trials were recorded by high definition cameras. Then, based on the videorecord, the checklist was filled in by two independent researchers.

After the verification of the questionnaire there were a series of experiments at elementary schools. The MABC-2, was performed on all participants recommended by the psychologist. Then, according to the results of the TTS, 32 children, aged 7-10 ( $8.7 \pm 1.1$ years), were categorized into two groups. According to the rules for interpretation of MABC-2, children with a TTS $\leq 15^{\text {th }}$ percentile were included in the $\mathrm{DCD}_{\mathrm{r}}$ group. Children with TTS $>15^{\text {th }}$ percentile were included in the TD group.

The $\mathrm{DCD}_{\mathrm{r}}$ group included 16 children, aged $8.2 \pm 0.7$ years, $\quad 131.1 \pm 7.7 \mathrm{~cm}$ body height, $30.9 \pm 8.9 \mathrm{~kg}$ body weight. In the TD group were included 16 children, aged $9.2 \pm 1.1$ years, $138.2 \pm 6.9 \mathrm{~cm}$ body height, $31.7 \pm 6.7 \mathrm{~kg}$ body weight. The TTS of the MABC-2 test was lower in the DCD $_{r}$ group ( $9.3 \pm 4.9$ percentile) with a clinical significance $(p<.001, d=3.64)$ as compared to the TD group $(61.8 \pm 19.8$ percentile $)$. All these children were mentally healthy, had no signs of other disorder such as ADHD, autism, cerebral palsy, previous traumatic brain injury, muscular dystrophy, epilepsy, blindness or deafness. There were no significant differences between both motor competence groups in relation to age, body height and body weight. The only difference between them was a lower score in a performance of 
the MABC-2. All participants were able to understand and carry out the tasks.

The results of Shapiro-Wilk test showed that data in different groups and conditions were distributed normally.

The first step of the research was finding differences between the DCD, group and the TD group. The analysis showed differences in the head $(F([1,30]=5.758$, $\left.p=.023, \quad \eta_{\mathrm{p}}^{2}=.161\right) \quad$ and $\operatorname{arm} \quad(F[1,30]=9.196$, $\left.p=.005, \quad \eta_{\mathrm{p}}^{2}=.235\right)$ movements, in body position $\left(F[1,30]=11.194, p=.002, \eta_{\mathrm{p}}^{2}=.272\right)$ and in the total summary score $\left(F[1,30]=14.466, p=.001, \eta_{\mathrm{p}}^{2}=.325\right)$ (Table 1).

The main effects of visual conditions were significant in all cases; in the head $(F[2.256,67.691]=4.221$, $\left.p=.015, \eta_{\mathrm{p}}^{2}=.123\right), \operatorname{arm}(F([2.096,62.870]=5.347$, $\left.p=.006, \eta_{\mathrm{p}}^{2}=.151\right), \operatorname{trunk}(F[1.569,47.064]=5.876$, $\left.p=.009, \quad \eta_{\mathrm{p}}^{2}=.164\right), \operatorname{leg}(F[2.641,79.236]=6.397$, $\left.p=.001, \quad \eta_{\mathrm{p}}^{2}=.176\right)$ movements, in body position $\left(F[1.251,37.515]=14.576, p=.001, \eta_{\mathrm{p}}^{2}=.327\right)$ and also in total summary score $(F[1.971,59.142]=8.591$, $\left.p=.001, \eta_{\mathrm{p}}^{2}=.223\right)$. The interaction between groups and visual conditions was significant in the leg movements $\left(F[2.641,79.236]=4.543, p=.007, \eta_{p}^{2}=.132\right)$ and body position $(F[1.251,37.515]=9.661, p=.002$, $\left.\eta_{\mathrm{p}}^{2}=.244\right)($ Table 2).

Based on these results a post-hoc test (Bonferonni) demonstrated in the leg movements, that TD-FV > $\mathrm{DCD}_{\mathrm{r}}-\mathrm{NV}(p=.004), \mathrm{DCD}_{\mathrm{r}}-\mathrm{FV}>\mathrm{DCD}_{\mathrm{r}}-\mathrm{NV}(p=.002)$, TD-LV150 > DCD-NV $(p=.006)$, TD-LV100> $\mathrm{DCD}_{\mathrm{r}}-\mathrm{NV}(p=.001)$.
In the body positions the post-hoc test showed, that children from the $\mathrm{DCD}_{\mathrm{r}}$ group in NV were significantly worse $(p<.001)$ than children in all other conditions, meaning: TD-FV > DCD-NV, TD-LV100 > DCD-NV, TD-LV150 > DCD-NV, TD-NV > DCD-NV, $\mathrm{DCD}_{\mathrm{r}}-\mathrm{FV}>\mathrm{DCD}_{\mathrm{r}}-\mathrm{NV}, \mathrm{DCD}_{\mathrm{r}}-\mathrm{LV} 100>\mathrm{DCD}_{\mathrm{r}}-\mathrm{NV}$, $\mathrm{DCD}_{\mathrm{r}}-\mathrm{LV} 150>\mathrm{DCD}_{\mathrm{r}}-\mathrm{NV}$.

The post-hoc test showed that in the body position, children in the TD group in the FV condition are better (it means they obtained less negative points for incorrect movements) than children from the $\mathrm{DCD}_{\mathrm{r}}$ group in the NV condition, children in the TD group in LV100 condition are better than children from the $\mathrm{DCD}_{\mathrm{r}}$ group in NV condition, children in the TD group in LV150 condition are better than children from the $\mathrm{DCD}_{\mathrm{r}}$ group in NV condition, children in the TD group in NV condition are better than children from the $\mathrm{DCD}_{\mathrm{r}}$ group in NV condition. Post-hoc also demonstrated that children from the $\mathrm{DCD}_{\mathrm{r}}$ group were better in FV condition than in NV condition, they are also better in LV100 condition than in NV condition. They had also better results in LV150 than in NV condition. The worst score was reached by children from the $\mathrm{DCD}_{\mathrm{r}}$ group in $\mathrm{NV}$ condition which confirmed the assumptions - this condition was considered as the most difficult for both groups.

In the leg movements the post-hoc test showed, that children classified in the TD group with the FV condition were better than children from the $\mathrm{DCD}_{\mathrm{r}}$ group in NV condition. TD children were also better in LV150 condition than children from the $\mathrm{DCD}_{\mathrm{r}}$ group in NV condition. This also applies to TD children in

Table 1

Statistical outcomes by ANOVA for the differences in observed body segments between the TD group and the $D C D_{r}$ group

\begin{tabular}{lllccc}
\hline Segment position & Group & Mean $\pm S D$ & $F$ & $p$ & $\eta_{\mathrm{p}}^{2}$ \\
\hline Head movements & TD & $1.156 \pm 0.466$ & 5.758 & .023 & .161 \\
& DCD $_{\mathrm{r}}$ & $1.438 \pm 0.530$ & & & \\
Arm movements & $\mathrm{TD}$ & $2.172 \pm 1.106$ & 9.196 & .005 & .235 \\
& $\mathrm{DCD}_{\mathrm{r}}$ & $2.922 \pm 0.896$ & & & \\
Trunk movements & $\mathrm{TD}$ & $0.125 \pm 0.333$ & 2.858 & .101 & .087 \\
& $\mathrm{DCD}$ & $0.328 \pm 0.618$ & & & \\
Leg movements & $\mathrm{TD}$ & $0.359 \pm 0.515$ & 3.085 & .089 & .093 \\
& $\mathrm{DCD}_{\mathrm{r}}$ & $0.656 \pm 0.820$ & & & \\
Body position & $\mathrm{TD}$ & $0.016 \pm 0.125$ & 11.194 & .002 & .272 \\
& $\mathrm{DCD}_{\mathrm{r}}$ & $0.172 \pm 0.419$ & & & \\
Total summary score & $\mathrm{TD}$ & $3.734 \pm 1.171$ & 14.466 & .001 & .325 \\
& $\mathrm{DCD}_{\mathrm{r}}$ & $4.891 \pm 1.129$ & & & \\
\hline
\end{tabular}

Note. $\quad \mathrm{TD}=$ typically developing, $\mathrm{DCD}_{\mathrm{r}}=$ risk of developmental coordination disorder, $F=$ variance of the group means, $p=$ statistical significance, $\eta_{\mathrm{p}}^{2}=$ effect size. 
Table 2

Means of errors, standard deviations and post-hoc analyses of observed body segments in different visual conditions

\begin{tabular}{|c|c|c|c|c|}
\hline Segment position & Condition & Mean $\pm S D$ & Pairwise comparisons & $p$ \\
\hline \multirow[t]{4}{*}{ Head movements } & $\mathrm{FV}$ & $1.281 \pm 0.508$ & \multirow[t]{4}{*}{ LV150 - NV } & \multirow[t]{4}{*}{.020} \\
\hline & LV150 & $1.156 \pm 0.508$ & & \\
\hline & LV100 & $1.250 \pm 0.447$ & & \\
\hline & $\mathrm{NV}$ & $1.500 \pm 0.567$ & & \\
\hline \multirow[t]{4}{*}{ Arm movements } & FV & $2.094 \pm 1.279$ & \multirow[t]{4}{*}{ FV - LV100 } & \multirow[t]{4}{*}{.040} \\
\hline & LV150 & $2.719 \pm 1.110$ & & \\
\hline & LV100 & $2.844 \pm 0.851$ & & \\
\hline & $\mathrm{NV}$ & $2.531 \pm 0.879$ & & \\
\hline \multirow[t]{4}{*}{ Trunk movements } & $\mathrm{FV}$ & $0.125 \pm 0.336$ & \multirow[t]{4}{*}{ no differences } & \\
\hline & LV150 & $0.188 \pm 0.396$ & & \\
\hline & LV100 & $0.125 \pm 0.336$ & & \\
\hline & $\mathrm{NV}$ & $0.469 \pm 0.761$ & & \\
\hline \multirow[t]{4}{*}{ Leg movements } & FV & $0.344 \pm 0.545$ & \multirow{4}{*}{$\begin{array}{c}\text { FV - NV } \\
\text { LV150 - NV }\end{array}$} & \multirow{4}{*}{$\begin{array}{l}.015 \\
.019\end{array}$} \\
\hline & LV150 & $0.406 \pm 0.715$ & & \\
\hline & LV100 & $0.438 \pm 0.559$ & & \\
\hline & $\mathrm{NV}$ & $0.844 \pm 0.846$ & & \\
\hline \multirow[t]{4}{*}{ Body position } & FV & $0.000 \pm 0.000$ & \multirow{4}{*}{$\begin{array}{c}\text { FV - LV100 } \\
\text { LV150 - LV100 }\end{array}$} & \multirow{4}{*}{$\begin{array}{l}.031 \\
.031\end{array}$} \\
\hline & LV150 & $0.000 \pm 0.000$ & & \\
\hline & LV100 & $0.031 \pm 0.176$ & & \\
\hline & $\mathrm{NV}$ & $0.083 \pm 0.545$ & & \\
\hline \multirow[t]{4}{*}{ Total summary score } & $\mathrm{FV}$ & $3.656 \pm 1.138$ & \multirow{4}{*}{$\begin{array}{c}\mathrm{FV}-\mathrm{NV} \\
\mathrm{LV} 150-\mathrm{NV}\end{array}$} & \multirow{4}{*}{$\begin{array}{l}.006 \\
.032\end{array}$} \\
\hline & LV150 & $4.125 \pm 1.268$ & & \\
\hline & LV100 & $4.438 \pm 0.906$ & & \\
\hline & NV & $5.031 \pm 1.942$ & & \\
\hline
\end{tabular}

Note. $\mathrm{FV}=$ full vision, $\mathrm{LV} 150=$ limited vision $150, \mathrm{LV} 100=$ limited vision $100, \mathrm{NV}=$ non vision, $p=$ statistical significance.

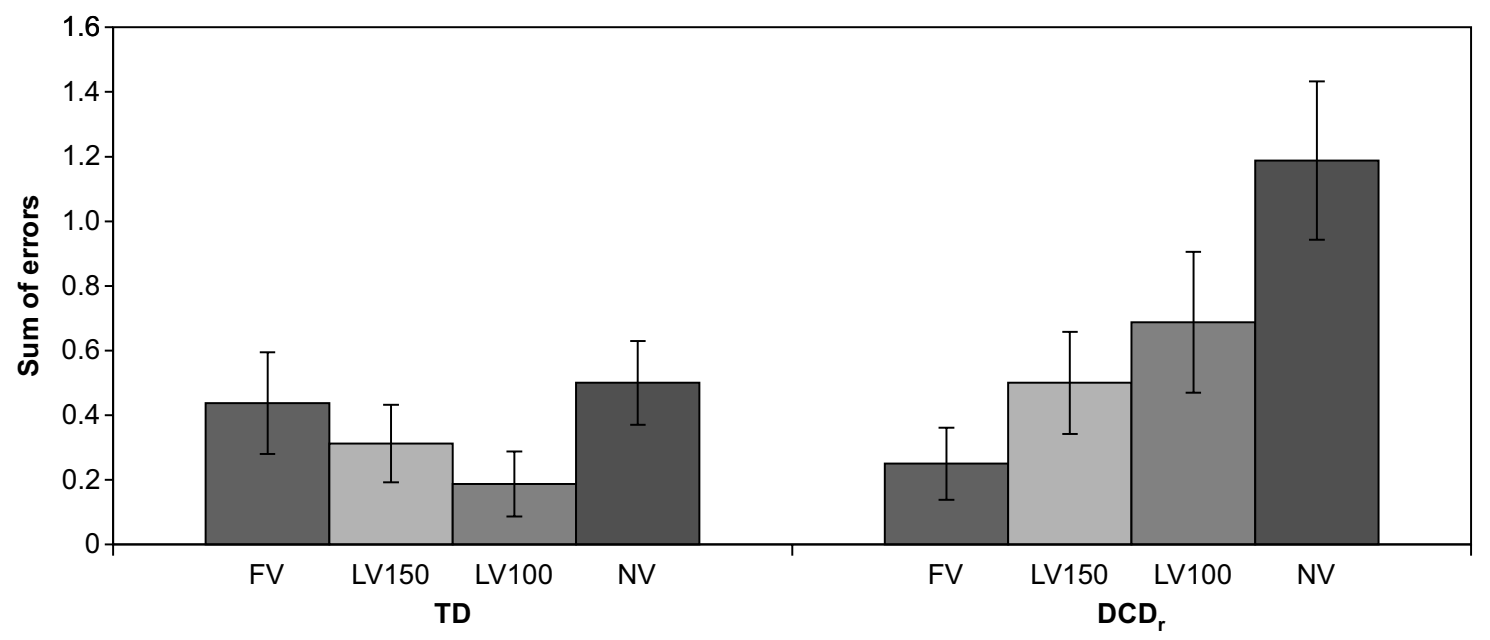

Figure 2. Means of sum of errors in different groups and visual conditions. Error bars represent standard errors of the mean. $\mathrm{TD}=$ typically developing, $\mathrm{DCD}_{\mathrm{r}}=$ risk of developmental coordination disorder. $\mathrm{FV}=$ full vision, $\mathrm{LV} 150=$ limited vision $150, \mathrm{LV} 100=$ limited vision $100, \mathrm{NV}=$ non vision 
LV100 condition - they were better than children from the $\mathrm{DCD}_{\mathrm{r}}$ group in NV condition. Children from the $\mathrm{DCD}_{\mathrm{r}}$ group had better results in $\mathrm{FV}$ condition than in NV condition.

\section{Discussion}

The main aim of this study was to create a checklist, which would show the differences between children with DCD (resp. DCD r $_{\text {) }}$ and TD children while walking based on observation. The experiment showed that the single items of the questionnaire were chosen correctly, which confirmed the obtained results. In addition, the results of the questionnaire confirmed the results from test battery MABC-2.

The next step was to find how large is the impact of different visual conditions for body segments while walking. The results showed that the main effects of visual conditions was significant in all cases - in head movements, arm movements, trunk movements, leg movements, body position and also in the total summary score. Especially the most difficult condition non vision (NV) - was consistent for children with $\mathrm{DCD}_{\mathrm{r}}$; the number of incorrect movements of body segments was strong compared to other conditions. Receiving visual information is critical with children for static postural control also for dynamic stability (Cherng, Liang, Chen, \& Chen, 2007). Moreover, the important role that vision plays in the control of dynamic stability in adults is also well documented (Cromwell, Newton, \& Forrest, 2002; Rietdyk \& Rhea, 2006).

Vision is one of the systems that affect balance along with the vestibular and proprioceptive systems. The relative importance of the visual information versus vestibular and proprioceptive feedback is different based on the children's age. But there are also several differences between DCD children and those with TD. When vision is removed the accuracy of the movement is more affected in children with DCD than with TD children (van Waelvelde, De Weerdt, De Cock, \& Smits-Engelsman, 2004).

It is rather complicated to compare these findings with other studies, because the majority of other studies are focused on static tasks and differences are measured at the level of skeletal muscles by electromyography (Fong, Tsang, \& Ng, 2012; Geuze, 2005). There is a possibility to find several studies where leg movements (Deconinck et al., 2006a; Missiuna et al., 2003; Wilson \& MacKenzie, 1998) confirmed the differences in children under various visual conditions while walking, but these studies focused mainly on TD children and the differences were observed mainly from a biomechanical point of view (gait cycle) (Parker \& Larkin, 2003; Woodruff, Bothwell-Myers, Tingley, \& Albert, 2002).

However, it is possible, that some differences are so small that it is not possible to detect them without specific equipment. This is likely to be in the case of trunk movements or leg movements, where we did not find differences. There are studies with a different result, especially in leg movements (Deconinck et al., 2006a; Parker \& Larkin, 2003; Woodruff et al., 2002). However, these studies are based on specific motion tasks, and they also have used special equipment for measurement. Another reason might be limited number of the participants in this study, which could also affect the significance of the results.

\section{Conclusion}

Despite all these facts, the total summary score from our checklist showed significant differences between groups and finally, the results of the checklist confirmed the results from MABC-2. This means, that children who were included in the $\mathrm{DCD}_{\mathrm{r}}$ group based on the results of the MABC-2, also reached the checklist score, which clearly pointed to problems with movement difficulties while walking. Therefore, it can be concluded, that the checklist is a suitable basic tool for detecting primary movement difficulties in children which may indicate problems with DCD.

\section{Acknowledgment}

This work was supported by the EU Structural Funds under the project Support for Creating Excellent Research Teams and Intersectoral Mobility at Palacký University in Olomouc I. (reg. no. CZ.1.07/2.3.00/30.0004) and II. (reg. no. CZ.1.07/2.3.00/30.0041).

\section{References}

American Psychiatric Association. (2013). The diagnostic and statistical manual of mental disorders. Washington, DC: Author.

Bo, J., \& Lee, C. M. (2013). Motor skill learning in children with developmental coordination disorder. Research in Developmental Disabilities, 34, 2047-2055.

Carlton, L. G. (1981). Visual information: The control of aiming movements. The Quarterly Journal of Experimental Psychology, 33, 87-93.

Cermak, S. A., Gubbay, S. S., \& Larkin, D. (2002). What is developmental coordination disorder? In S. A. Cermak 
\& D. Larkin (Eds.), Developmental Coordination Disorder (pp. 2-22). Albany, NY: Thomson Learning.

Cheatum, B. A., \& Hammond, A. A. (2000). Physical activities for improving children's learning and behavior: A guide to sensory motor development. Champaign, IL: Human Kinetics.

Cherng, R. J., Liang, L. Y., Chen, Y. J., \& Chen, J. Y. (2009). The effects of a motor and a cognitive concurrent task on walking in children with developmental coordination disorder. Gait \& Posture, 29, 204-207.

Coetzee, D., \& Pienaar, A. E. (2010). The role of visual functions in persisting developmental coordination disorder (DCD) among 7 year old children: A follow-up study: Kinderkinetics. African Journal for Physical Health Education, Recreation and Dance, 16, 251-264.

Cousins, M., \& Smyth, M. M. (2003). Developmental coordination impairments in adulthood. Human Movement Science, 22, 433-459.

Cromwell, R. L., Newton, R. A., \& Forrest, G. (2002). Influence of vision on head stabilization strategies in older adults during walking. The Journals of Gerontology Series A: Biological Sciences and Medical Sciences, 57, M442-M448.

Deconinck, F. J. A., De Clercq, D., Savelsbergh, G. J. P., Van Coster, R., Oostra, A., Dewitte, G., \& Lenoir, M. (2006a). Visual contribution to walking in children with developmental coordination disorder. Child: Care, Health and Development, 32, 711-722.

Deconinck, F. J. A., De Clercq, D., Savelsbergh, G. J. P., Van Coster, R., Oostra, A., Dewitte, G., \& Lenoir, M. (2006b). Differences in gait between children with and without developmental coordination disorder. Motor Control, 10, 125-142.

Fong, S. S., Tsang, W. W., \& Ng, G. Y. (2012). Altered postural control strategies and sensory organization in children with developmental coordination disorder. Human Movement Science, 31, 1317-1327.

Geuze, R. H. (2005). Postural control in children with developmental coordination disorder. Neural Plasticity, 12, 183-196.

Gillberg, I. C., Gillberg, C., \& Groth, J. (1989). Children with preschool minor neurodevelopmental disorders, V: Neurodevelopmental profiles at age 13. Developmental Medicine \& Child Neurology, 31, 14-24.

Hellgren, L., Gillberg, C., Gillberg, I. C., \& Enerskog, I. (1993). Children with deficits in attention, motor control and perception (DAMP) almost grown up: General health at 16 years. Developmental Medicine \& Child Neurology, 35, 881-892.

Henderson, S. E., Barnett, A., \& Henderson, L. (1994). Visuospatial difficulties and clumsiness: On the interpretation of conjoined deficits. Journal of Child Psychology and Psychiatry, 35, 961-969.

Henderson, S. E., Sugden, D. A., \& Barnett, A. L. (2007). Movement assessment battery for children - 2: Movement $A B C$-2: Examiner's manual. London: Pearson.

Larkin, D., \& Hoare, D. (1991). Out of step. Nedlands, Australia: The University of Western Australia.

Lundy-Ekman, L., Ivry, R., Keele, S., \& Woollacott, M. (1991). Timing and force control deficits in clumsy children. Journal of Cognitive Neuroscience, 3, 367-376.
Macnab, J. J., Miller, L. T., \& Polatajko, H. J. (2001). The search for subtypes of DCD: Is cluster analysis the answer? Human Movement Science, 20, 49-72.

Missiuna, C., Rivard, L., \& Bartlett, D. (2003). Early identification and risk management of children with developmental coordination disorder. Pediatric Physical Therapy, $15,32-38$.

Parker, H. E., \& Larkin, D. (2003). Children's co-ordination and developmental movement difficulty. In G. Savelsberg, J. Davids, J. van der Kamp, \& S. J. Bennett (Eds.), Development of movement co-ordination in children (pp. 107-132). New York, NY: Routledge.

Paulignan, Y., MacKenzie, C., Marteniuk, R., \& Jeannerod, M. (1991). Selective perturbation of visual input during prehension movements. Experimental Brain Research, 83, 502-512.

Pélisson, D., Prablanc, C., Goodale, M. A., \& Jeannerod, M. (1986). Visual control of reaching movements without vision of the limb. Experimental Brain Research, 62, 303-311.

Polatajko, H. J. (1999). Developmental coordination disorder (DCD): Alias the clumsy child syndrome. In K. Whitmore, H. Hart, \& G. Williams (Eds.), Clinics in developmental medicine: A neurodevelopmental approach to specific learning disorders (pp. 119-133). London: MacKeith Press.

Psotta, R., Hendl, J., Frömel, K., \& Lehnert, M. (2012). The second version of the Movement Assessment Battery for Children: A comparative study in 7-10 year old children from the Czech Republic and the United Kingdom. Acta Universitatis Palackianae. Gymnica, 42(4), 19-27.

Raynor, A. J. (2001). Strength, power, and coactivation in children with developmental coordination disorder. Developmental Medicine \& Child Neurology, 43, 676-684.

Rietdyk, S., \& Rhea, C. K. (2006). Control of adaptive locomotion: Effect of visual obstruction and visual cues in the environment. Experimental Brain Research, 169, 272-278.

Rosengren, K. S., Deconinck, F. J., DiBerardino, L. A., Polk, J. D., Spencer-Smith, J., De Clercq, D., \& Lenoir, M. (2009). Differences in gait complexity and variability between children with and without developmental coordination disorder. Gait \& Posture, 29, 225-229.

Schoemaker, M. M., van der Wees, M., Flapper, B., VerheijJansen, N., Scholten-Jaegers, S., \& Geuze, R. H. (2001). Perceptual skills of children with developmental coordination disorder. Human Movement Science, 20, 111-133.

Smith, W. M., \& Bowen, K. F. (1980). The effects of delayed and displaced visual feedback on motor control. Journal of Motor Behavior, 12, 91-101.

Smyth, M. M., Anderson, H. I., \& Churchill, A. (2001). Visual information and the control of reaching in children: A comparison between children with and without developmental coordination disorder. Journal of Motor Behavior, 33, 306-320.

Spijkers, W. A., \& Lochner, P. (1994). Partial visual feedback and spatial end-point accuracy of discrete aiming movements. Journal of Motor Behavior, 26, 283-295.

Steindl, R., Kunz, K., Schrott-Fischer, A., \& Scholtz, A. W. (2006). Effect of age and sex on maturation of sensory systems and balance control. Developmental Medicine \& Child Neurology, 48, 477-482. 
Van Waelvelde, H., De Weerdt, W., De Cock, P., \& SmitsEngelsman, B. C. M. (2004). Aspects of the validity of the Movement Assessment Battery for Children. Human Movement Science, 23, 49-60.

Wann, J. P., Mon-Williams, M., \& Carson, J. (1998). Assessing manual control in children with coordination difficulties. In K. J. Connolly (Ed.), Psychobiology of the hand (pp. 213-229). London: MacKeith Press.
Wilson, P. H., \& McKenzie, B. E. (1998). Information processing deficits associated with developmental coordination disorder: A meta-analysis of research findings. Journal of Child Psychology and Psychiatry, 39, 829-840.

Woodruff, S. J., Bothwell-Myers, C., Tingley, M., \& Albert, W. J. (2002). Gait pattern classification of children with developmental coordination disorder. Adapted Physical Activity Quarterly, 19, 378-391. 